03

\title{
Воспламенение топливной смеси с помощью многоточечного импульсного искрового разряда при различных начальных условиях
}

\author{
() П.В. Булат, ${ }^{1}$ К.Н. Волков, ${ }^{2}$ Л.П. Грачев, ${ }^{3}$ И.И. Есаков, ${ }^{3}$ П.Б. Лавров ${ }^{3}$ \\ ${ }^{1}$ Балтийский государственный технический университет „ВОЕНМЕХ“ им. Д.Ф. Устинова, \\ 190005 Санкт-Петербург, Россия \\ ${ }^{2}$ Университет Кингстона, \\ SW15 3DW, Лондон, Великобритания \\ ${ }^{3}$ Московский радиотехнический институт РАН, \\ 117519 Москва, Россия \\ e-mail: dsci@mail.ru
}

Поступило в Редакцию 31 марта 2021 г.

В окончательной редакции 16 апреля 2021 г.

Принято к публикации 17 апреля 2021 г.

Разработка эффективных и надежных систем зажигания топливных смесей представляет интерес для многих практических приложений, связанных с использованием энергетических установок с горением. Для увеличения суммарной поверхности пламени, обеспечения надежности воспламенения, повышения скорости горения в объеме камеры и полноты сгорания горючей смеси находит применение многоточечное зажигание топливной смеси при помощи нескольких импульсных искровых разрядов. На основе данных физического эксперимента проведено сравнение характеристик продуктов сгорания в рабочей камере при использовании различного количества поджигающих искровых разрядов. Измерения проведены при различных точках поджига смеси, начальных давлениях смеси, коэффициентах избытка топлива в смеси относительно стехиометрического соотношения. Значения коэффициента избытка топлива, используемые в эксперименте, находятся в интервале, границами которого служат нижний и верхний концентрационные пределы воспламенения пропано-воздушной смеси.

Ключевые слова: искровой разряд, горение, топливная смесь, коэффициент избытка горючего.

DOI: 10.21883/JTF.2021.09.51212.92-21

\section{Введение}

Обеспечение полного сгорания топлива в двигателях внутреннего сгорания и газотурбинных установках, уменьшение содержания вредных веществ в выхлопных газах, снижение потребления топлива и повышение мощности двигателей, требует разработки новых и совершенствования существующих систем поджигания горючей смеси. Основная проблема при разработке систем зажигания топливных смесей состоит в необходимости повышения надежности воспламенения без существенного повышения энергетических затрат на процесс зажигания [1].

Известные устройства для зажигания топливных смесей различаются видом воспламеняющих физических средств $[2,3]$. Для поджигания топливных смесей находят применение электрические разряды разного типа [4-6], импульсное лазерное излучение [7-9], микроволновый СВЧ-разряд [10-13], воздушные плазмотроны [14]. В газодинамическом принципе зажигания топлива реакция горения инициируется нагревом топливной смеси на поверхности полого газодинамического резонатора, разогрев которого осуществляется за счет собственной внутренней энергии сжатого газа при возбуждении акустических колебаний. При разработке воспламенительных устройств топливных смесей используется эффект теп- ловыделения, возникающий при взаимодействии до- и сверхзвуковых струй с трубной полостью [15-17], а также газовые импульсные резонаторы [18-21].

Во многих системах зажигания применяется подход, когда в искровом промежутке свечи зажигания создается импульсный искровой разряд. Использование нескольких источников зажигания, распределенных по длине камеры сгорания (многоточечное зажигание), увеличивает суммарную поверхность пламени, обеспечивая надежность воспламенения, повышение скорости горения в объеме камеры и полноту сгорания горючей смеси [22]. При этом горение происходит с повышением давления и конечной температуры продуктов горения.

Процессы, происходящие в газе при искровом разряде, и повышение надежности воспламенения топливовоздушной смеси рассматриваются во многих работах [23-27]. Объемное сгорание позволяет увеличить скорость сгорания топлива, снизить склонность к появлению детонации и поднять степень сжатия топливовоздушной смеси. Несмотря на достигнутые научнотехнические результаты, связанные с повышением полноты сгорания топлива в тепловых двигателях, улучшением их удельных характеристик и уменьшением эмиссии вредных веществ, для повышения надежности воспламенительных систем требуются дополнительные 


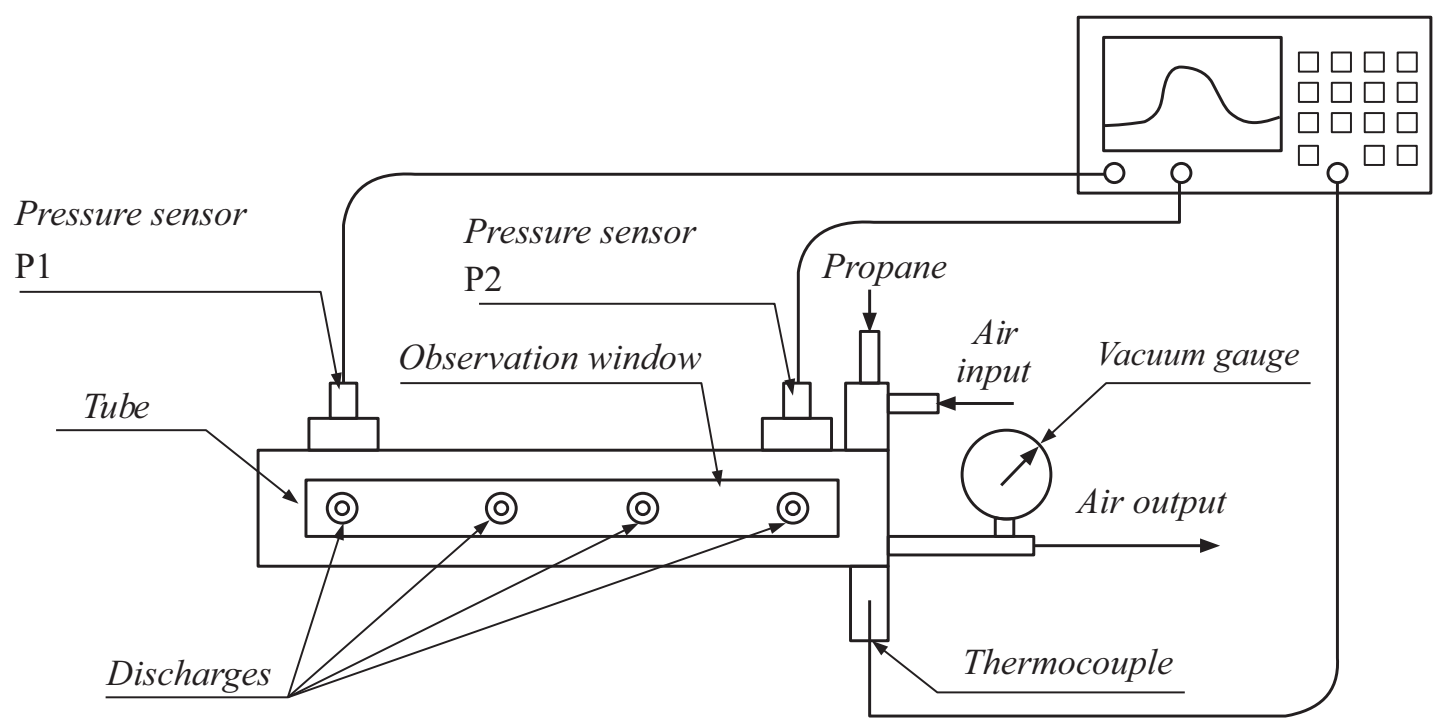

Pис. 1. Схема трубы экспериментальной установки и расположение датчиков.

исследования многоточечных (многоочаговых) систем поджигания топливных смесей.

В настоящей работе проводится экспериментальное исследование горения пропано-воздушной смеси, для воспламенения которой используется искровая система зажигания. На основе полученных данных сравниваются скорости распространения фронта пламени, времена заполнения пламенем объема рабочей камеры, скорости нарастания давления и максимальные давления в камере в зависимости от числа точек поджига, начального давления в камере и состава горючей смеси. Находится оптимальный коэффициент избытка пропана, при котором достигается максимальное давление в камере сгорания.

\section{1. Экспериментальная установка}

Экспериментальный стенд, спроектированный и разработанный в МРТИ РАН, позволяет проводить эксперименты с поджигом горючих смесей с помощью классической системы зажигания, используя автомобильные свечи зажигания. Схему рабочей трубы стенда со всеми необходимыми датчиками показывает рис. 1. Камера сгорания по размерам примерно соответствует цилиндру двигателя грузового автомобиля. Длина цилиндрической камеры сгорания составляет $280 \mathrm{~mm}$, а ее радиус $40 \mathrm{~mm}$. Установка имеет два смотровых окна (боковое и торцевое), через которые производится видеосъемка процесса воспламенения на скоростную камеру Nicon D1 со скоростью 400 кадров/с. Благодаря этим видеозаписям можно оценить скорость распространения фронта пламени и время горения пламени.

Для зажигания искровых свечей используется электронная схема с высоковольтным накопительным конденсатором, коммутируемым через ограничительные ре- зисторы на необходимое количество свечей зажигания. Основное преимущество такой схемы поджига свечей заключается в возможности выделения большой энергии за малый промежуток времени, что необходимо для обеспечения устойчивого искрообразования и сравнительной простоты получения искры практически любой мощности и энергии. Добиться этого с обычной транзисторной или тиристорной схемой оказывается достаточно затруднительным.

Свечи зажигания типа А17ДВ с межэлектродным зазором $0.7 \mathrm{~mm}$ подключены к схеме поджига с помощью силиконовых высоковольтных проводов обычной автомобильной системы зажигания через ограничительные резисторы. Их сопротивление изначально равняется $R_{i}=100 \mathrm{k} \Omega$, а затем для повышения мощности искры последовательно уменьшается до $R_{i}=30$, $15,10 \mathrm{k} \Omega$ (в ряде случаев - до $5 \mathrm{k} \Omega$ ). Поскольку при этом длительность разряда накопителя (длительность искры) также уменьшается, емкость накопителя энергии $(\mathrm{C} 4-\mathrm{C} 21)$ увеличивается с $0.24 \mu \mathrm{F}$ сначала до $0.74 \mu \mathrm{F}$, а позже - до $1.8 \mu \mathrm{F}$. При этом в каждом эксперименте емкость накопителя выбирается такой, что длительность искры остается постоянной при различном количестве $N$ подключаемых к системе свечей: $C(N)=N(0.2-0.25) \mu \mathrm{F}$ при $N=1, \ldots, 8$ или $C(N)=N(0.4-0.45) \mu \mathrm{F}$ при $N=1, \ldots, 4$. Свечи устанавливают с равномерным шагом. В случае использования 8 свечей шаг между ними составляет $40 \mathrm{~mm}$. Откачка продуктов сгорания производится после завершения процессов горения. Полная энергия одного разряда составляет $350-400 \mathrm{~mJ}$. В качестве источника разряда применяются обычные автомобильные свечи зажигания.

Для измерения давления в трубе используются электронные дифференциальные датчики типа 24PCGFA6D. Для снижения возможных помех сигнала от датчиков в 
том числе по цепям питания (помеха с частотой $50 \mathrm{~Hz}$ ) предусмотрено их автономное питание от батареек и размещение самих датчиков и источников их питания в экранирующем металлическом корпусе, переходные фланцы которых присоединяются непосредственно к соответствующим фланцам трубы, в которой измеряется давление. Схема источника питания датчиков состоит из батарейного отсека, тумблера выключения питания, стабилизатора напряжения на $10 \mathrm{~V}$ типа K78L10AZTA, нагруженного на выводы датчика давления. Измеряемый сигнал с выводов датчика через коаксиальный разъем типа СР-50 экранированным кабелем подается на осциллограф VellemanPclab-2000LT. Верхний предел измеряемого давления датчика 24PCGFA6D составляет $1724 \mathrm{kPa}$.

Сигнал с дифференциального электронного датчика давления регистрируется и запоминается с помощью осциллографа, подсоединенного к компьютеру. Значения давления записываются каждые $50 \mu \mathrm{s}$. Эксперименты показывают, что нет необходимости измерять давления двумя датчиками одновременно (P1 и Р2), поскольку временная задержка между ними не существенна (скорость звука в воздухе составляет около $300 \mathrm{~m} / \mathrm{s}$ ).

В ходе экспериментов выявлена проблема, связанная c образованием нагара в камере сгорания, который мешает нормальной съемке. Наибольшее количество нагара наблюдается в экспериментах при давлении свыше $1.5 \mathrm{~atm}$ и в богатых смесях при $\eta>1$. Это связано с тем, что пропан не сгорает, и частично сажа (несгоревший компонент горючей смеси) оседает на стенках камеры в том числе на смотровом окне, через которое производится видеосьемка. После нескольких экспериментов окно снимается и чистится. Кроме того, на свечах зажигания также образуется налет, в связи с чем свечи демонтируются и чистятся после нескольких экспериментов.

В экспериментах варьируется ряд параметров. Количество поджигающих разрядов составляет 1,4 и 8 . Начальное давление смеси равняется 0.5, 1.5, 2 и 2.5 бар. Изменяется также состав смеси (соотношение пропана к воздуху). Измерения проводятся при коэффициентах избытка пропана в смеси относительно стехиометрического соотношения в интервале от 0.6 до 2. При других значениях коэффициента избытка горючего смесь не воспламеняется. Используемые значения коэффициента избытка топлива близки к верхнему и нижнему концентрационному пределу воспламенения пропановоздушной смеси.

\section{2. Результаты и обсуждение}

В экспериментах изменяется количество поджигающих искровых разрядов, число которых составляет 1 (вариант 1), 4 (вариант 2) и 8 (вариант 3). В качестве источника разрядов служат обычные автомобильные свечи зажигания.

\section{1. Поджиг в одной точке}

В варианте 1 смесь поджигается только в одной точке, которая располагается на расстоянии $4 \mathrm{~cm}$ от левого торца камеры. Длина всей камеры составляет $40 \mathrm{~cm}$.

В качестве примера распространения пламени на рис. 2 приводятся фотографии горения пропановоздушной смеси при начальном давлении $2 \mathrm{~atm}$ и коэффициенте избытка пропана $\eta=1.17$ с интервалом $10 / 400=25 \mathrm{~ms}$. Приведенные фотографии позволяют определить скорость фронта пламени, время заполнения пламенем всей камеры и время всего процесса горения смеси.

Из анализа приведенных видеокадров следует, что скорость распространения фронта пламени составляет около $4 \mathrm{~m} / \mathrm{s}$. Эта скорость слабо зависит от состава смеси. Максимальная скорость достигается при коэффициенте избытка пропана $\eta=1.2$. Основное отличие заключается в том, что в бедной смеси яркость пламени очень слабая (энергии выделяется мало). В смеси, близкой к стехиометрическому отношению при изменении $\eta$ от 0.7 до 1.6, скорость фронта пламени практически не изменяется и составляет $3.5 \ldots 4 \mathrm{~m} / \mathrm{s}$, а в богатых смесях при $\eta=1.7$ и выше скорость падает до $2 \mathrm{~m} / \mathrm{s}$ (возрастает время всего горения). Кроме того, при горении обогащенных смесей при $\eta>1.2$ цвет пламени оранжевый. Это говорит о том, что пропан сгорает не полностью. В случае с сильно обедненными смесями при $\eta<0.6$ более медленного горения не наблюдается, смесь перестает гореть в принципе.

Зависимости давления в трубе от времени показывает рис. 3 при различных начальных давлениях. По гори-

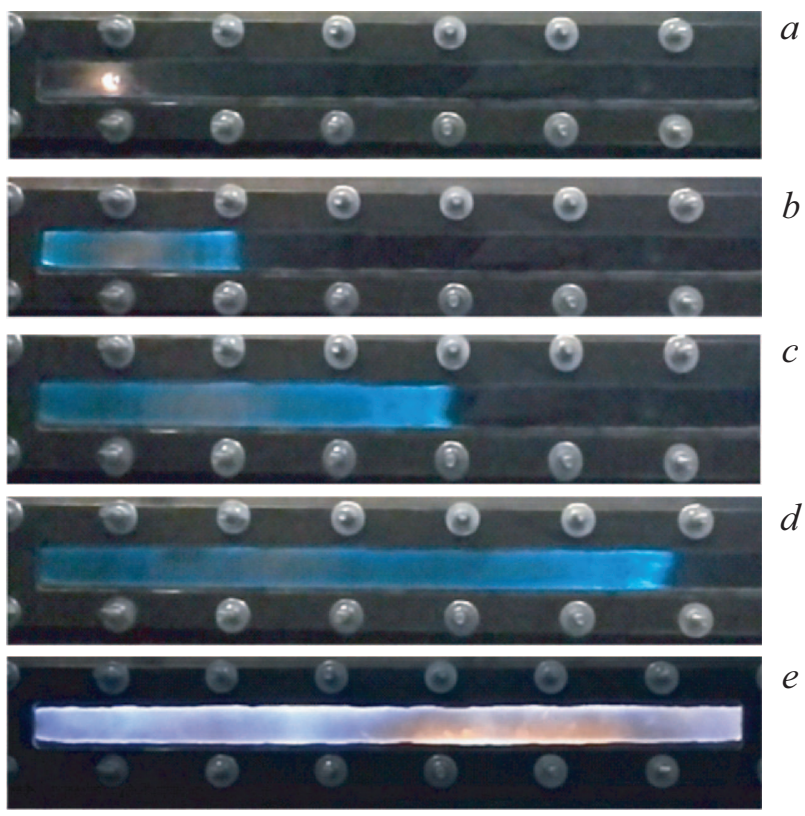

Рис. 2. Поджиг в одной точке. Фотографии пламени для состава смеси при $\eta=1.17$ в моменты времени, соответствующие поджигу смеси $(a), 10 / 400(b), 20 / 400(c), 30 / 400(d)$, $40 / 400$ s $(e)$. 

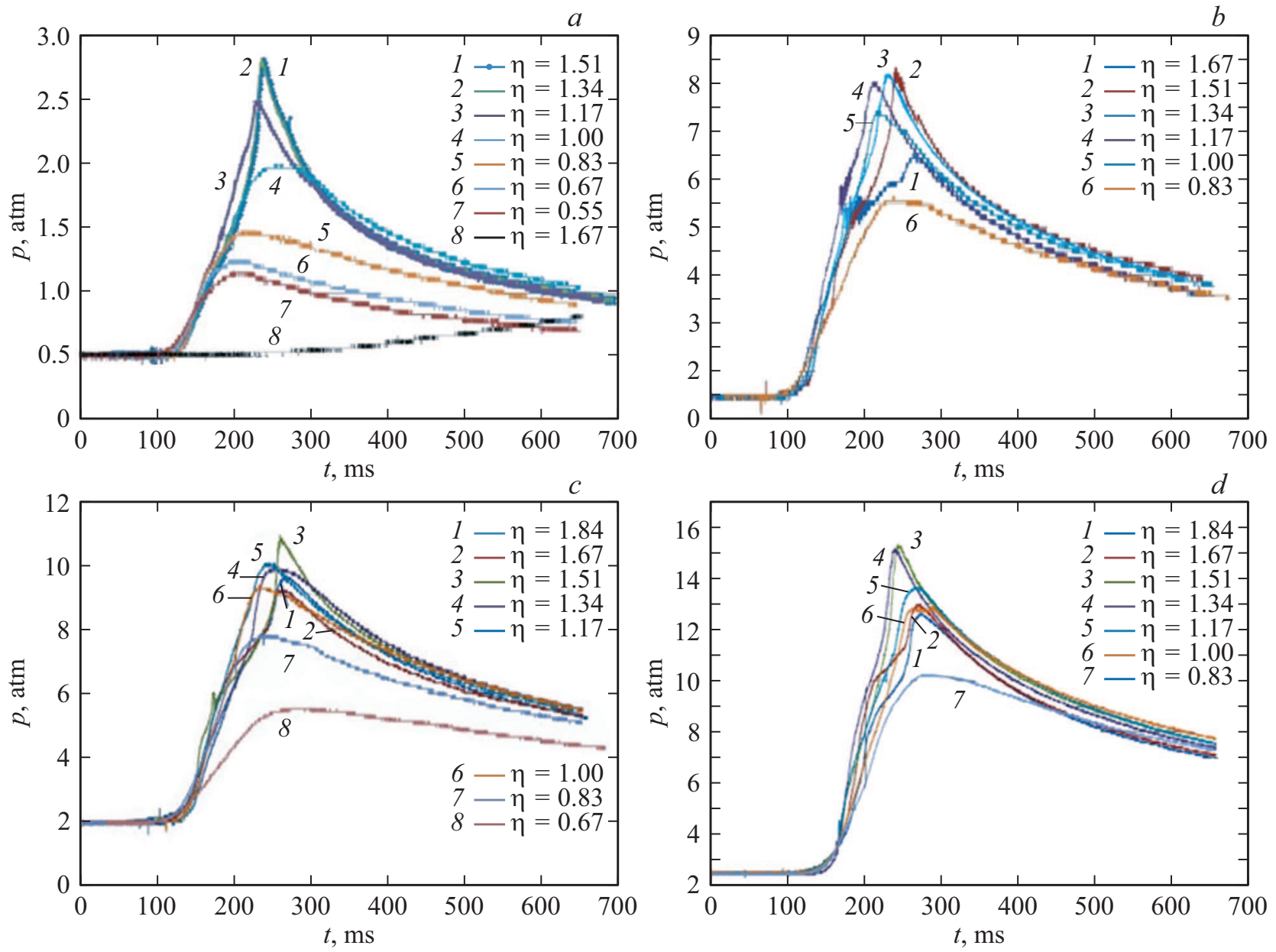

Рис. 3. Поджиг в одной точке. Зависимости давления в камере от времени при различных начальных давлениях: $p_{0}=0.5(a)$, $1.5(b), 2(c), 2.5 \mathrm{~atm}(d)$.

зонтальной оси откладывается время протекания процесса горения, начиная с поджига и заканчивая полным сгоранием смеси, а по вертикальной оси - давление в камере. На каждом графике представлены несколько линий, каждая из которых соответствует горению с различным коэффициентом избытка пропана в смеси. Время роста давления практически не зависит от коэффициента избытка горючего и составляет около $150 \mathrm{~ms}$. При изменении состава смеси изменяется максимальное давление процесса горения, которое достигает максимального значения при $\eta=1 \ldots 1.5$. Следовательно, скорость роста давления является максимальной при этих значениях коэффициента избытка горючего.

В табл. 1 приводятся основные характеристики процессов горения при начальном давлении пропановоздушной смеси в экспериментальной трубе $p_{0}=2 \mathrm{~atm}$. Под $\eta$ понимается коэффициент избытка пропана в пропано-воздушной смеси, $p_{\max }$ - давление в камере, $t_{p}$ - время роста давления до $p_{\max }, v_{p}$ - скорость подъема давления от $p_{0}$ до $p_{\max }, t_{v}-$ время заполнения пламенем всего объема, $t_{b}$ - время сгорания смеси.
Таблица 1. Поджиг в одной точке. Зависимости параметров горения от состава смеси при начальном давлении $p_{0}=2$ bar

\begin{tabular}{c|l|l|c|c|c|c}
\hline № & \multicolumn{1}{|c|}{$\eta$} & $p_{\max }, \mathrm{bar}$ & $t_{p}, \mathrm{~ms}$ & $v_{p}, \mathrm{~atm} / \mathrm{s}$ & $t_{v}, \mathrm{~ms}$ & $t_{b}, \mathrm{~ms}$ \\
\hline 1 & 0.66 & 3.7 & 160 & 23 & 100 & 230 \\
2 & 0.83 & 6 & 120 & 50 & 85 & 240 \\
3 & 1 & 7.15 & 120 & 60 & 78 & 305 \\
4 & 1.17 & 8.5 & 120 & 71 & 75 & 290 \\
5 & 1.34 & 8.5 & 140 & 60 & 78 & 450 \\
6 & 1.51 & 9.7 & 140 & 70 & 85 & 400 \\
7 & 1.67 & 6.9 & 160 & 43 & 78 & 500 \\
8 & 1.84 & 6.5 & 160 & 40 & 132 & 550 \\
9 & 2 & - & - & - & - & -
\end{tabular}

\section{2. Поджиг в четырех точках}

В варианте 2 эксперименты проводятся с четырьмя точками поджига. Фотографии, показывающие распространение фронта пламени, приводятся на рис. 4 для коэффициента избытка горючего $\eta=1$ и начального давления в камере $p_{0}=2 \mathrm{~atm}$. В сравнении с одной 
свечой зажигания в данном случае время, за которое фронт пламени занимает весь объем камеры, составляет
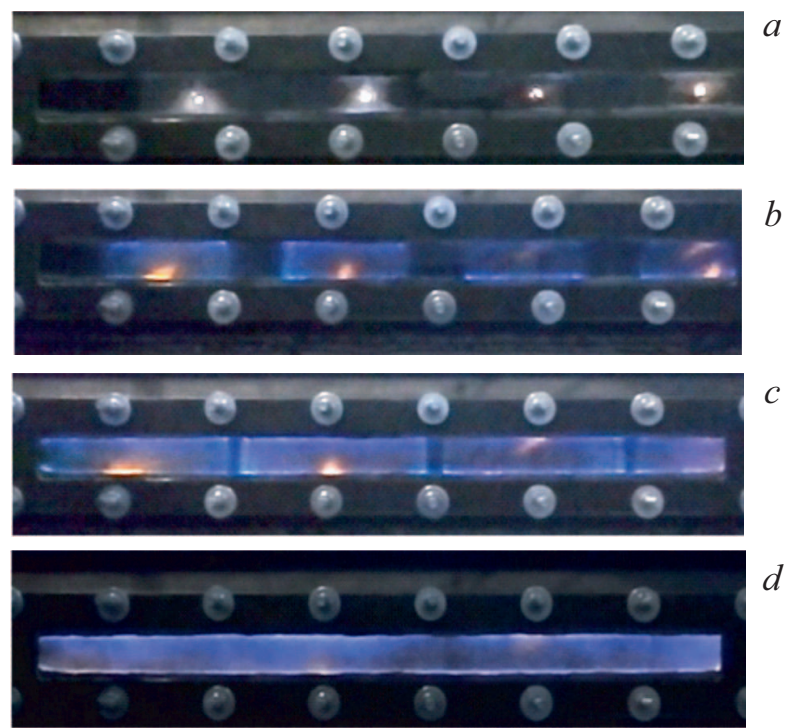

Pис. 4. Поджиг в четырех точках. Фотографии пламени для состава смеси при $\eta=1$ в моменты времени, соответствующие поджигу смеси $(a), 5 / 400(b), 10 / 400(c), 15 / 400(d)$.
$15 / 400 \mathrm{~s}$ (38 ms), что в 2.7 раза быстрее, чем с одной свечой в варианте 1. Время увеличивается не пропорционально увеличению числу точек поджига (в данном случае их число равняется 4). Скорее всего, это связанно с тем, что пламя, уже начавшееся от соседней точки поджига, увеличивает давление в камере, в связи с чем скорость фронта пламени уменьшается.

Зависимости давления в трубе от времени показывает рис. 5 при различных начальных давлениях.

Зависимости максимального давления газа в трубе от состава смеси приводятся на рис. 6 (по горизонтальной оси откладывается коэффициент избытка пропана в смеси, а по вертикальной оси - давление в камере). Каждая линия соответствует различным начальным давлениям смеси (от 0.5 до $2.5 \mathrm{~atm}$ ). При увеличении исходного давления в трубе растет и максимальное давление процесса сгорания, причем эта зависимость практически линейная. Например, максимальное давление при $p_{0}=0.5 \mathrm{~atm}$ равняется $p_{\max }=2.5 \mathrm{~atm}$, а при $p_{0}=2.5 \mathrm{~atm}$ имеем, что $p_{\max }=13.5 \mathrm{~atm}$. Линейная зависимость сохраняется при всех начальных давлениях. При этом изменяется лишь само значение максимального давления, которое зависит от состава смеси (коэффициента избытка пропана в смеси).
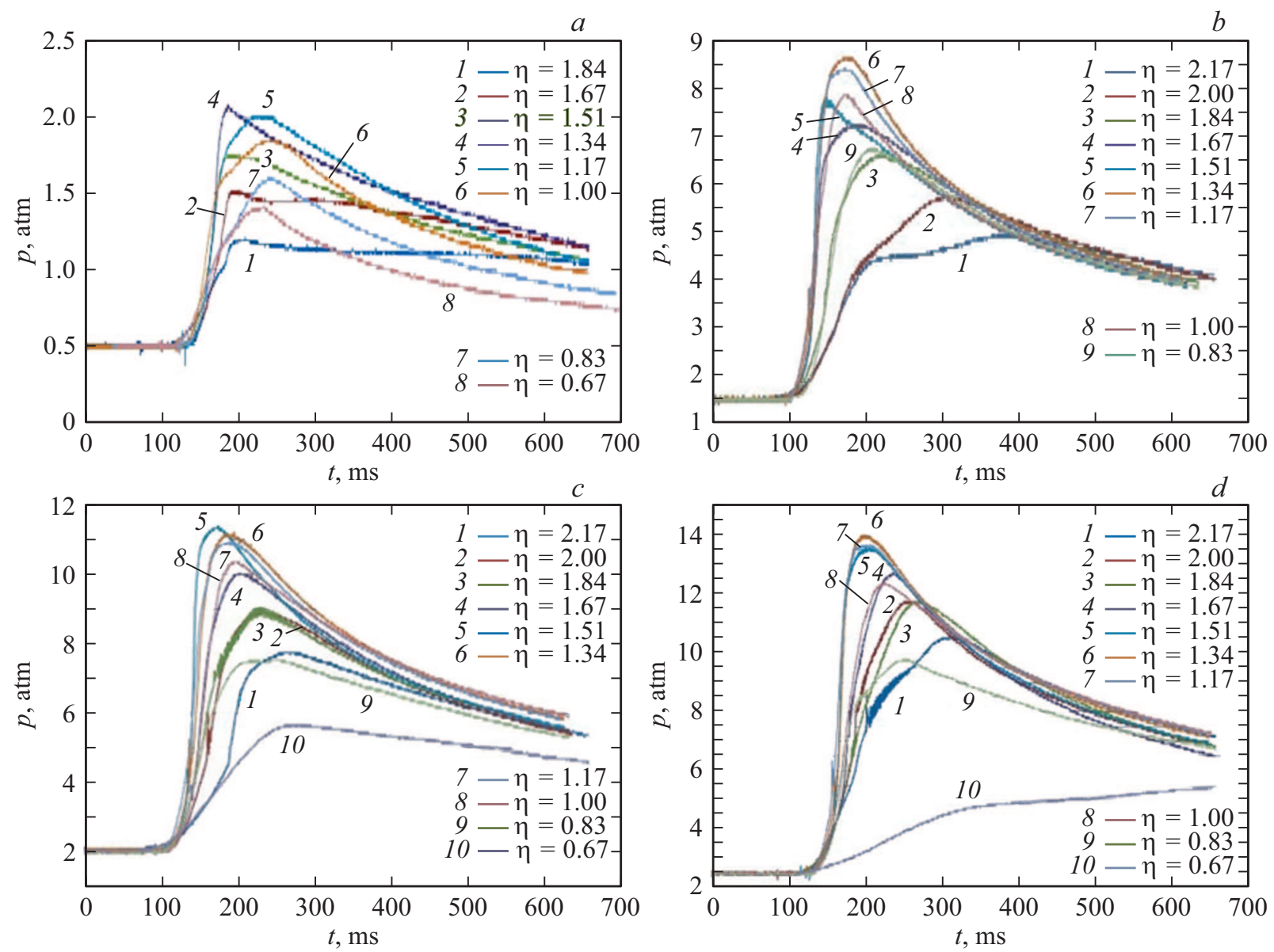

Рис. 5. Поджиг в четырех точках. Зависимости давления в камере от времени при различных начальных давлениях: $p_{0}=0.5(a)$, $1.5(b), 2(c), 2.5 \mathrm{~atm}(d)$. 


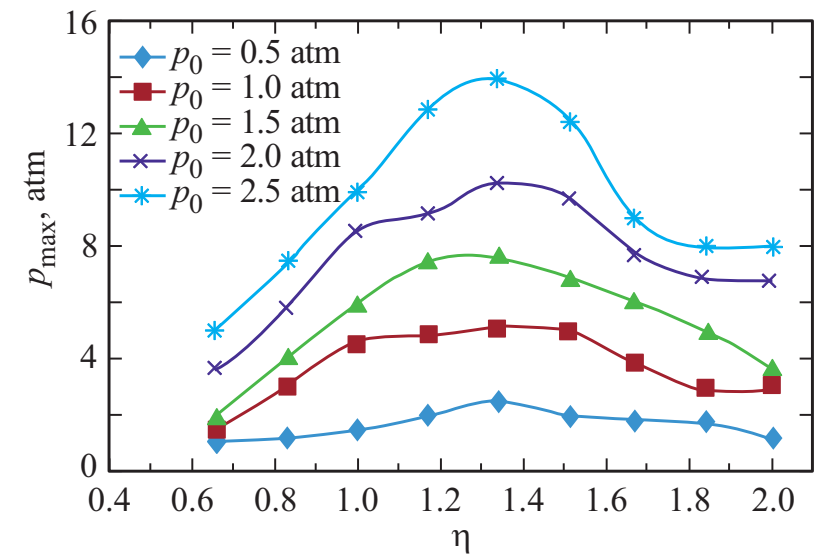

Pис. 6. Поджиг в четырех точках. Зависимости максимального давления в трубе от состава смеси при различных начальных давлениях.

Таблица 2. Поджиг в четырех точках. Зависимости параметров горения от состава смеси при начальном давлении $p_{0}=2$ bar

\begin{tabular}{c|l|c|c|c|c|c}
\hline № & \multicolumn{1}{|c|}{$\eta$} & $p_{\max }$, bar & $t_{p}, \mathrm{~ms}$ & $v_{p}$, atm/s & $t_{v}, \mathrm{~ms}$ & $t_{b}, \mathrm{~ms}$ \\
\hline 1 & 0.66 & 3.7 & 180 & 21 & 45 & 275 \\
2 & 0.83 & 5.8 & 110 & 53 & 33 & 275 \\
3 & 1 & 8.5 & 90 & 94 & 35 & 350 \\
4 & 1.17 & 9.2 & 90 & 103 & 33 & 425 \\
5 & 1.34 & 9.3 & 80 & 116 & 30 & 450 \\
6 & 1.51 & 9.7 & 70 & 139 & 33 & 440 \\
7 & 1.67 & 7.8 & 100 & 78 & 45 & 475 \\
8 & 1.84 & 6.9 & 120 & 58 & 45 & 575 \\
9 & 2 & 6.8 & 120 & 45 & 48 & 590
\end{tabular}

В табл. 2 приводятся основные характеристики процессов горения при начальном давлении пропановоздушной смеси в экспериментальной трубе при $p_{0}=2 \mathrm{~atm}$.

\section{3. Поджиг в восьми точках}

В варианте 3 эксперименты проводятся с восемью точками поджига. Фотографии, показывающие распространение фронта пламени, приводятся на рис. 7 для коэффициента избытка горючего $\eta=1$ и начального давления в камере $p_{0}=2 \mathrm{~atm}$. В данном случае время, за которое пламя заполняет весь объем камеры, еще сильнее уменьшается по сравнению с четырьмя свечами (вариант 2) и составляет $9 / 400=23 \mathrm{~ms}$, что в 1.5 раз быстрее, чем в варианте 2. Нелинейность сокращения времени сохраняется.

Зависимости давления в трубе от времени показывает рис. 8 при различных начальных давлениях.

В табл. 3 приводятся основные характеристики процессов горения при начальном давлении пропановоздушной смеси в экспериментальной трубе при
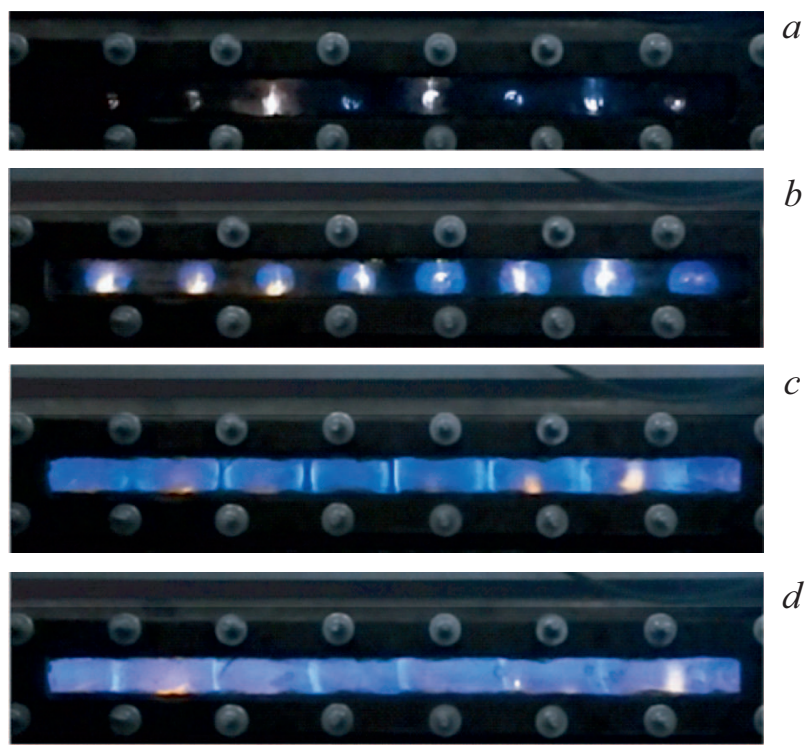

Рис. 7. Поджиг в восьми точках. Фото пламени для состава смеси при $\eta=1$ в моменты времени, соответствующие поджигу смеси $(a), 3 / 400(b), 6 / 400(c), 9 / 400 \mathrm{~s}(d)$.

Таблица 3. Поджиг в восьми точках. Зависимости параметров горения от состава смеси при начальном давлении $p_{0}=2 \mathrm{bar}$

\begin{tabular}{c|l|l|r|c|c|c}
\hline № & \multicolumn{1}{|c|}{$\eta$} & $p_{\max }$, bar & $t_{p}, \mathrm{~ms}$ & $v_{p}, \mathrm{~atm} / \mathrm{s}$ & $t_{v}, \mathrm{~ms}$ & $t_{b}, \mathrm{~ms}$ \\
\hline 1 & 0.66 & 5 & 160 & 31 & 30 & 260 \\
2 & 0.83 & 7 & 120 & 70 & 25 & 250 \\
3 & 1 & 9.1 & 80 & 113 & 20 & 350 \\
4 & 1.17 & 11.1 & 75 & 145 & 20 & 350 \\
5 & 1.34 & 11.6 & 50 & 216 & 20 & 470 \\
6 & 1.51 & 10.4 & 45 & 231 & 24 & 450 \\
7 & 1.67 & 8.1 & 80 & 101 & 27 & 470 \\
8 & 1.84 & 7.8 & 120 & 65 & 40 & 490 \\
9 & 2 & 6.9 & 140 & 50 & 45 & 500
\end{tabular}

$p_{0}=2$ atm. При восьми точках поджига время нарастания давления уменьшается приблизительно в 1.5 раза по сравнению с экспериментами, в которых используется четыре точки поджига (вариант 2), и приблизительно в три раза быстрее, чем в случае с одной точкой поджига (вариант 1).

\section{3. Обобщение результатов}

Зависимости максимального давления в трубе при оптимальном коэффициенте избытка пропана от начального давления пропано-воздушной смеси показаны на рис. 9. Максимальное давление горения не зависит от количества точек поджига. Оно зависит только от состава смеси и начального давления. Максимальное давление во всех случаях приблизительно в пять раз больше, чем начальное давление. 

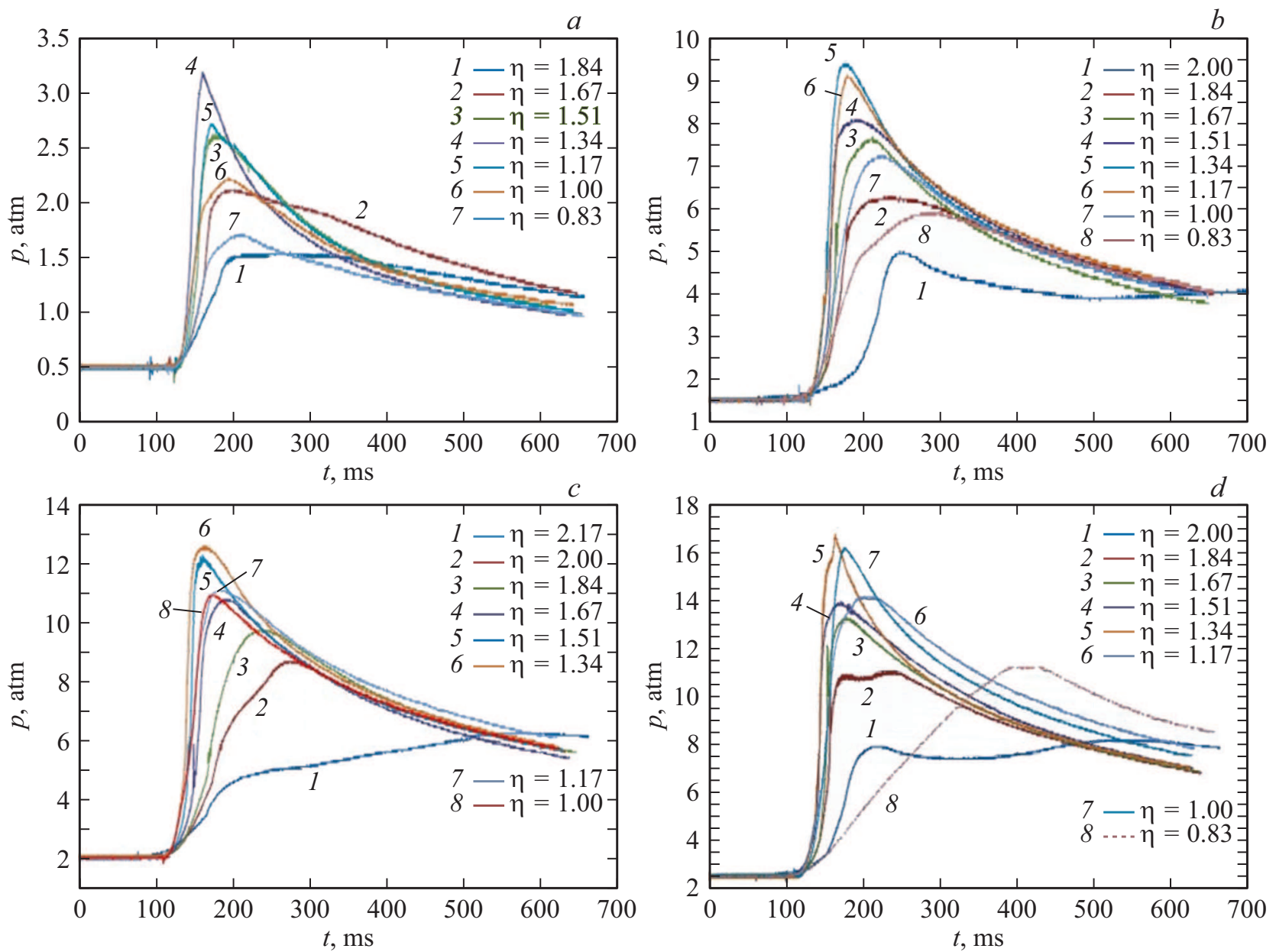

Рис. 8. Поджиг в восьми точках. Зависимости давления в камере от времени при различных начальных давлениях: $p_{0}=0.5(a)$, $1.5(b), 2(c), 2.5 \mathrm{~atm}(d)$.

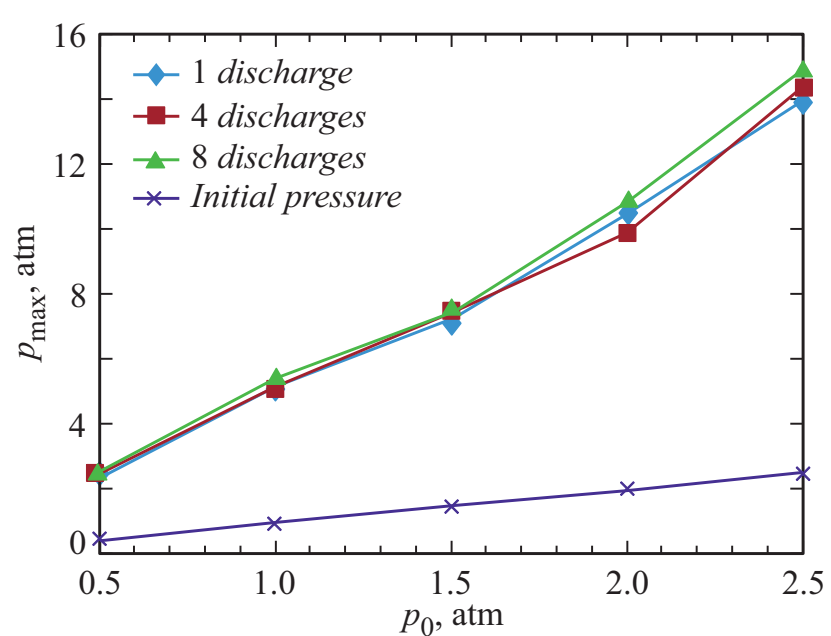

Рис. 9. Зависимости максимального давления в трубе при оптимальном коэффициенте избытка пропана в зависимости от начального давления.

Увеличение скорости подъема давления пропановоздушной смеси при горении находится из соотноше- ния $v_{p}=p_{\max } / t$. Зависимости скорости нарастания давления газов в трубе от коэффициента избытка пропана в смеси показывает рис. 10 при различном количестве точек поджига. В данном случае выбираются значения скоростей в экспериментах с начальным давлением пропано-воздушной смеси $p_{0}=2 \mathrm{~atm}$. При увеличении точек поджига увеличивается скорость нарастания давления. Эта зависимость является нелинейной. При одной точке поджига максимальная скорость нарастания давления составляет $v_{p}=70 \mathrm{~atm} / \mathrm{s}$, при четырех точках поджига $-v_{p}=140 \mathrm{~atm} / \mathrm{s}$, при восьми точках поджига $-v_{p}=230 \mathrm{~atm} / \mathrm{s}$. Данные зависимости с небольшой погрешностью сохраняются и при других начальных давлениях смеси в трубе.

С помощью скоростной видеосъемки получен еще один параметр горения - время заполнения пламенем всего объема трубы (следует отметить, что это не скорость фронта пламени). Скорость фронта пламени представляет собой непрерывный процесс распространения пламени в пространстве вдоль одной линии от начальной точки до конечной. В данном случае количество точек поджига изменяется, и направление движения пламени 


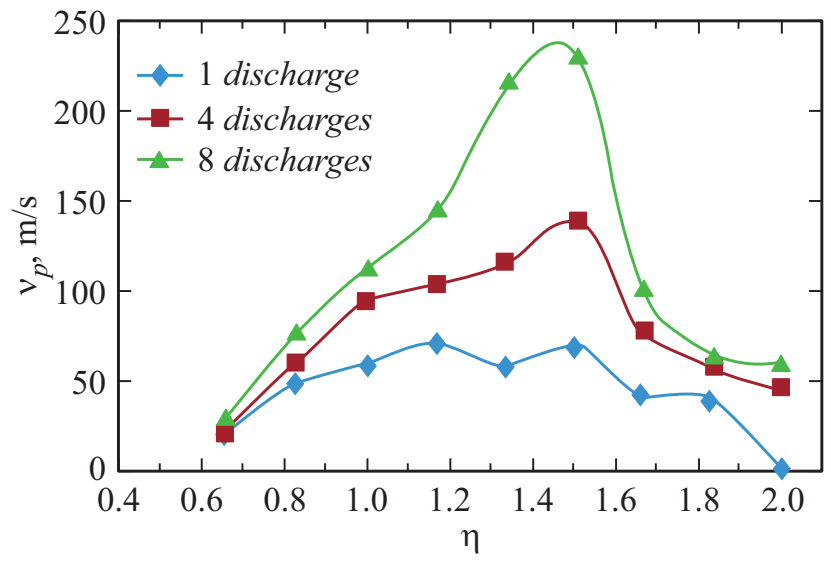

Рис. 10. Зависимости скорости нарастания давления от коэффициента избытка пропана в пропано-воздушной смеси при $p_{0}=2 \mathrm{~atm}$.

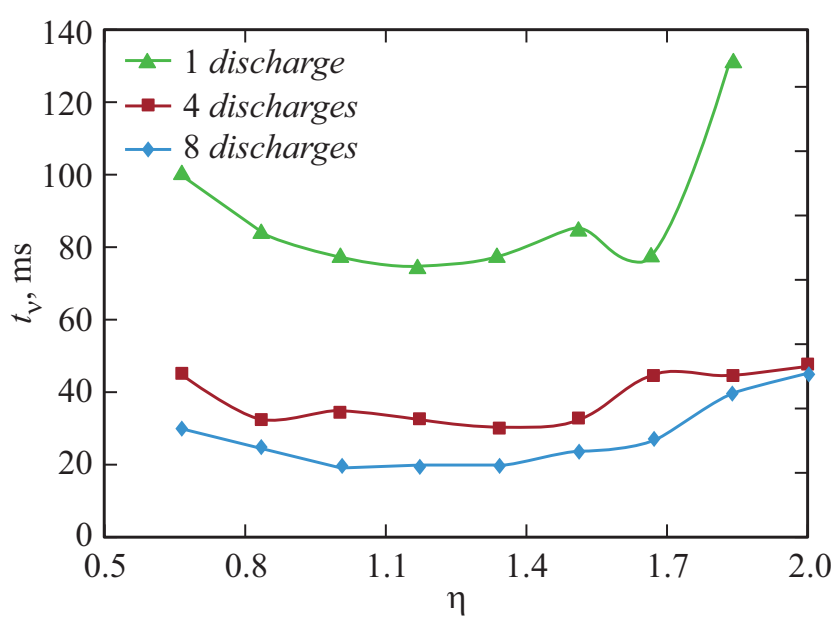

Рис. 11. Зависимости времени заполнения пламенем всего объема трубы от коэффициента избытка пропана в пропановоздушной смеси при $p_{0}=2 \mathrm{~atm}$.

следует учитывать в разные стороны относительно точки поджига (налево и направо). В случае с одной точкой поджига при $\eta=1 \ldots 1.5$ это время составляет $80 \mathrm{~ms}$, при четырех точках поджига - $35 \mathrm{~ms}$, при восьми точках поджига - $20 \mathrm{~ms}$. Такая зависимость является нелинейной (рис. 11), но количество точек поджига оказывает сильное влияние на уменьшении времени заполнения пламенем смеси.

Скорость фронта пламени измеряется только при одной точке поджига (ее наибольшее значение достигает $4 \mathrm{~m} / \mathrm{s}$ ). Скорость фронта пламени при нескольких точках поджига измерить не удается, поскольку в этом случае пламя распространяется скачкообразно (расстояние между разрядами не превышает $10 \mathrm{~cm}$ в случае с четырьмя разрядами и $5 \mathrm{~cm}$ в случае с восемью разрядами). Это расстояние пламя проходит с двух сторон (от двух соседних разрядов). Сами разряды немного отличаются друг от друга. В них выделяется разное количество энергии $(300-450 \mathrm{~mJ})$. На эту скорость также оказывают влияние неоднородности внутренней поверхности трубы, в связи с чем эти значения изменяются в очень широком интервале - от 1 до десятков $\mathrm{m} / \mathrm{s}$.

Время горения пропано-воздушной смеси от начала срабатывания свечи зажигания до полного исчезновения пламени (отсутствие свечение в камере сгорания) изменяется от $250 \mathrm{~ms}$ в экспериментах с бедными смесями $(\eta=0.6)$ до $600 \mathrm{~ms}$ в экспериментах с богатыми смесями $(\eta=2)$. Этот параметр практически не зависит от количества поджигающих точек. Можно сделать вывод, что количества точек поджига не увеличивает скорость сгорания смеси (время окислительного процесса).

\section{Заключение}

Проведены экспериментальные исследования по изучению горения пропано-воздушной смеси с применением искровой системы зажигания. На основе полученных видеоматериалов оценена скорость распространения фронта пламени, которая достигает $4 \mathrm{~m} / \mathrm{s}$. Время заполнения пламенем всего объема трубы зависит от количества точек поджига. Эта зависимость является нелинейной.

Измерены скорости нарастания давления в трубе при разных количествах точек поджига $(1,4$ и 8 искровых разрядов). При увеличении точек поджига скорость нарастания давления увеличивается, но не пропорционально увеличению их количества.

Выполнены эксперименты с различным стехиометрическим составом горючей смеси. Наибольшая скорость подъема давления в трубе достигается при коэффициенте избытка пропана в диапазоне от 1.1 до 1.5.

Измерены максимальные давления процессов горения в трубе при различных начальных давлениях в трубе. При наиболее благоприятных условиях (оптимальный коэффициент избытка пропана составляет $1.1-1.5)$ давление увеличивается в 5 раз относительно начального давления, и это значение остается постоянным вне зависимости от количества точек поджига.

\section{Финансирование работы}

Работа выполнена при финансовой поддержке Министерства науки и высшего образования Российской Федерации в ходе реализации проекта „Создание опережающего научно-технического задела в области разработки передовых технологий малых газотурбинных, ракетных и комбинированных двигателей сверхлегких ракет-носителей, малых космических аппаратов и беспилотных воздушных судов, обеспечивающих приоритетные позиции российских компаний на формируемых глобальных рынках будущего“, № FZWF-2020-0015.

\section{Конфликт интересов}

Авторы заявляют, что у них нет конфликта интересов. 


\section{Список литературы}

[1] R.M. Medvedev, A.P. Drozhzhin, V.S Teslenko. Intern. J. Multiphase Flow., 83, 232 (2016).

[2] Y. Ju, W. Sun. Prog. in Energ. Combustion Scien., 48, 21 (2015).

[3] J. Koch, J.M. Kutz. Phys. Fluids, 32, 126102 (16 p.) (2020).

[4] А.Ф. Александров, А.П. Ершов, С.А. Каменщиков, А.А. Логунов, В.А. Черников. Вестник МГУ. Сер. 3. Физика. Астрономия, 2, 63 (2008).

[5] R. Huang, H. Fukanuma, Y. Uesugi, Y. Tanaka. J. Thermal Spray Technol., 21 (3-4), 636 (2012).

[6] В.Я. Фролов, Д.В. Иванов, Ю.В. Мурашов, А.Д. Сиваев. Письма в ЖТФ, 41 (7), 8 (2015).

[7] А.А. Андронов, В.А. Гурин, А.В. Маругин, А.П. Савикин, Д.Е. Святошенко, А.Н. Тихомиров, Ю.С. Уткин, В.Л. Химич. Письма в ЖТФ, 40 (15), 66 (2014).

[8] V.N. Emelyanov, K.N. Volkov. Intern. J. Hydrogen Energy, 39 (11), 6222 (2014).

[9] P.V. Bulat, O.P. Minin, K.N. Volkov. Acta Astronautica, 150, 162 (2010).

[10] К.В. Александров, Л.П. Грачев, И.И. Есаков, В.В. Федоров, К.В. Ходатаев. ЖТФ, 76 (11), 52 (2006).

[11] M.P. Bulat, P.V. Bulat, P.V. Denissenko, I.I. Esakov, L.P. Grachev, K.N. Volkov, I.A. Volobuev. Acta Astronautica, 163, 33 (2019).

[12] P.V. Denissenko, M.P. Bulat, I.I. Esakov, L.P. Grachev, K.N. Volkov, I.A. Volobuev, V.V. Upyrev, P.V. Bulat. Combustion and Flame. 202, 417 (2019).

[13] A.I. Saifutdinov, E.V. Kustova, A.G. Karpenko, V.A. Lashkov. Plasma Phys. Reports, 45 (6), 602 (2019).

[14] Ф.А. Гизатуллин, В.Н. Худяев. Вестник УГАТУ, 9 (6(24)), 170 (2007).

[15] G. Raman, K. Srinivasan. Prog. in Aerospace Scien., 45 (4), 97 (2009).

[16] О.В. Бочарова, М.Г. Лебедев. Химическая физика, 30 (7), 40 (2011).

[17] О.В. Бочарова, М.Г. Лебедев. Инженерный журнал: наука и инновации, 9, 1 (2018).

[18] В.В. Семенов, Л.Ч. Мин, И.Э. Иванов, И.А. Крюков. Вестник МАИ, 11 (2), 22 (2004).

[19] К.Ю. Арефьев, А.В. Воронецкий, М.А. Ильченко. Физика горения и взрыва, 49 (6), 41 (2013).

[20] К.Н. Волков, В.Н. Емельянов, А.В. Ефремов, А.И. Цветков. Инженерно-физический журнал, 93 (5), 1220 (2020).

[21] К.Н. Волков, В.Н. Емельянов, А.В. Ефремов, А.И. Цветков. ЖТФ, 90 (8), 1254 (2020).

[22] И.А. Заев, В.В. Потапкин, С.А. Федоров, В.В. Куприк. Известия вузов. Авиационная техника, 2, 49 (2014).

[23] В.П. Карпов, В.В. Малов, Е.С. Северин. Физика горения и взрыва, 2, 3 (1986).

[24] Ф.И. Абрамчук, А.Н. Кабанов, А.П. Кузьменко, Э.Р. Муртазаев. Автомобильный транспорт, 27, 25 (2010).

[25] С.М. Францев, А.Ю. Кавторев. Современные проблемы науки и образования, 11, 1 (2015).

[26] М.Д. Гарипов. Автомобильная промышленность, 4, 8 (2010).

[27] М.Д. Гарипов, Р.Ю. Сакулин, Е.Н. Гарипов, Р.Ф. Зиннатуллин. Известия вузов. Авиационная техника, 1, 27 (2012). 